\title{
Conjugation Inhibitors and Early Neonatal Hyperbilirubinaemia
}

\author{
A. P. COLE and T. HARGREAVES \\ From the Departments of Paediatrics and Chemical Pathology, Royal Devon and Exeter (Heavitree) Hospital, \\ Exeter, Devon
}

Cole, A. P., and Hargreaves, T. (1972). Archives of Disease in Childhood, 47, 415. Conjugation inhibitors and early neonatal hyperbilirubinaemia. Milk and serum were obtained from 50 mothers on the 6th day post partum and examined for inhibitory activity against bilirubin conjugation in rat liver slices. Neonatal serum bilirubin levels were also analysed at this time. There was no relation between the amount of inhibitory substance in breast milk or serum and the degree of neonatal hyperbilirubinaemia. It was observed that inhibitory activity increased in frozen breast milk but not in frozen autoclaved breast milk.

The main cause of jaundice in neonates in the absence of a haemolytic process is thought to be defective conjugation of bilirubin in the liver. A number of other factors may be involved, since an increased incidence of jaundice is found in neonates whose sibs have had idiopathic neonatal jaundice (Brown and Zuelzer, 1957), in pregnancies complicated by antepartum haemorrhage, and in neonates who have asphyxia at birth or respiratory distress syndrome (Wood et al., 1962). Postmaturity and pre-eclamptic toxaemia decrease the incidence and severity of neonatal jaundice (Sacrez et al., 1960; Wood et al., 1962). A decreased incidence is also found in 'small-for-dates' babies (Sjöstedt, Engleson, and Rooth, 1958). Administration of barbiturates to women in the later stages of pregnancy has been shown to decrease serum bilirubin levels in their children because of the induction of the hepatic conjugating mechanisms for bilirubin (Ramboer, Thompson, and Williams, 1969).

Breast-fed infants have a higher incidence of hyperbilirubinaemia in the first week of life than is observed in bottle-fed infants (Arias and Gartner, 1970), and a prolonged unconjugated hyperbilirubinaemia is found in certain breast-fed infants (breast milk jaundice) (Arias et al., 1964). Prolonged severe unconjugated hyperbilirubinaemia may also be due to the presence of conjugation inhibitors in maternal serum (Arias et al., 1965). This present study is an attempt to assess the relevance of inhibitors of bilirubin conjugation

Received 12 October 1971. normally found in maternal serum and breast milk, to the degree of neonatal jaundice.

\section{Materials and Methods}

Fifty-two consecutive breast-fed infants born between 38th and 42nd week of gestational age were studied. They included two pairs of twins. Antenatal and birth histories were recorded and the infants were examined on the first and sixth day.

On the sixth day $5 \mathrm{ml}$ breast milk were obtained by expression, together with $5 \mathrm{ml}$ maternal blood for conjugation inhibitor studies. Also on the sixth day, bilirubin levels in the infants were determined by an ultramicroanalytical technique (Beckman Technical Bulletin). Haemoglobin and blood group determinations were performed routinely and direct antiglobulin, ficin and bromelin tests were done where incompatabilities were thought possible.

Male albino rats were used for the conjugation studies. Bilirubin conjugation by rat liver slices was determined from the amount of direct reacting bilirubin in the incubation medium of Lathe and Walker (1958a). $0.2 \mathrm{ml}$ breast milk was added to the incubation flasks and the rate of conjugation compared with control values. The effect of maternal serum on conjugation was determined by measuring the rate of conjugation of bilirubin by rat liver slices in medium in which the pooled human serum was replaced by maternal serum. This was compared with control values. All analyses were performed at least in duplicate. The results are expressed as percentage inhibition of conjugation when compared with control values.

The method of keeping human breast milk for analysis was investigated in detail. Normally milk for analysis is frozen until examined (Arias et al., 1964). Certain anomalous results suggested that the keeping properties 
of the inhibitor in milk should be examined more closely.

\section{Results}

Forty-nine infants had birthweights within 1 SD of the mean for infants of 38 to 42 weeks' gestation. 37 were normal healthy babies. No cases of $\mathrm{ABO}$ incompatability or direct antiglobulin positive haemolytic disease were found in the group.

The relation between the inhibitory activity of breast milk and the serum bilirubin level for all the infants is shown in Fig. 1. Fig. 2 shows the

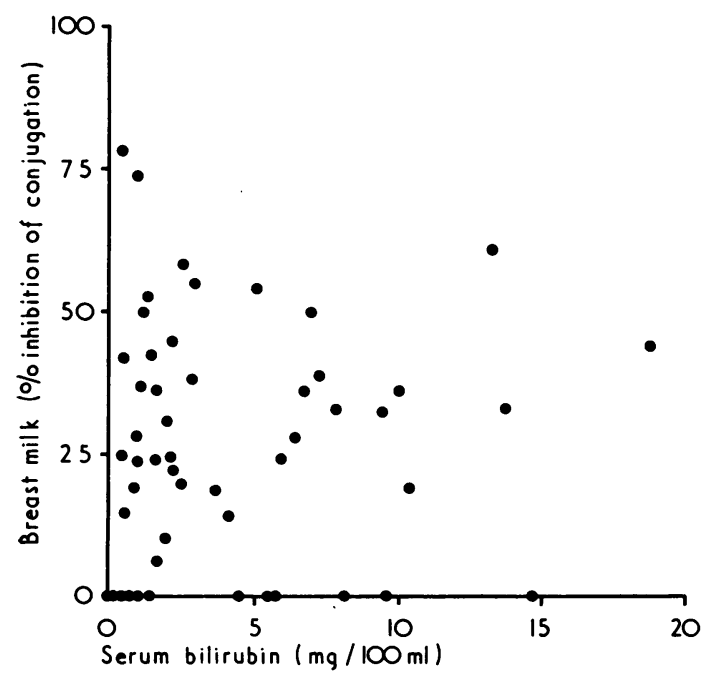

FIG. 1.-Relation between inhibitory activity of breast milk at 6 th day post partum and neonatal serum bilirubin levels.

relation between inhibitory activity of the maternal serum at 6 days and the neonatal serum bilirubin level. Fig. 3 shows the relation between percentage inhibition of bilirubin conjugation in rat liver slices obtained by adding breast milk to the system and that obtained by adding maternal serum. There is no correlation between the factors studied.

Of the infants studied 6 were postmature. 1 had birth asphyxia. 1 was 'small-for-dates', and this infant was polycythaemic ( $\mathrm{Hb} 21 \mathrm{~g} / 100 \mathrm{ml}$ ) as was one other child. 4 mothers were given barbiturates for toxaemia in the later stages of pregnancy, and 3 children were given phenobarbitone. The serum bilirubin of these infants did not differ from the control group, neither did the amount of inhibitory activity in maternal serum or breast milk.

All breast milks were examined as soon as possible after collection. This was because a group of 17 breast milks examined soon after

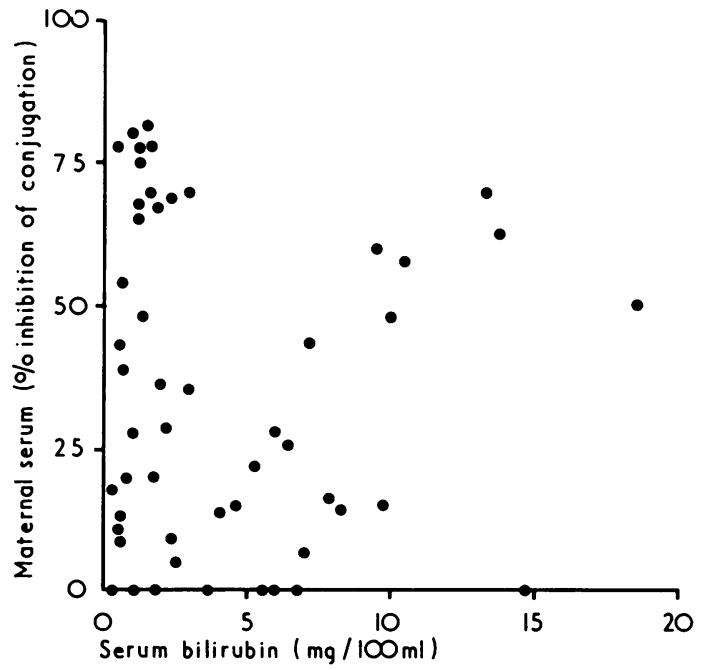

Fig. 2.-Relation between inhibitory activity of maternal serum at 6 th day post partum and neonatal serum bilirubin levels.

collection and again after keeping for 3 months at $-20{ }^{\circ} \mathrm{C}$ showed a mean increase in inhibitory activity from $33.0 \%$ to $53 \cdot 3 \%$. This was examined further by determining the inhibitory activity in samples of 'normal' breast milk and sterilized bank milk over a period of time (Fig. 4). The results show that inhibition may develop in a breast milk selected at random and that this did not

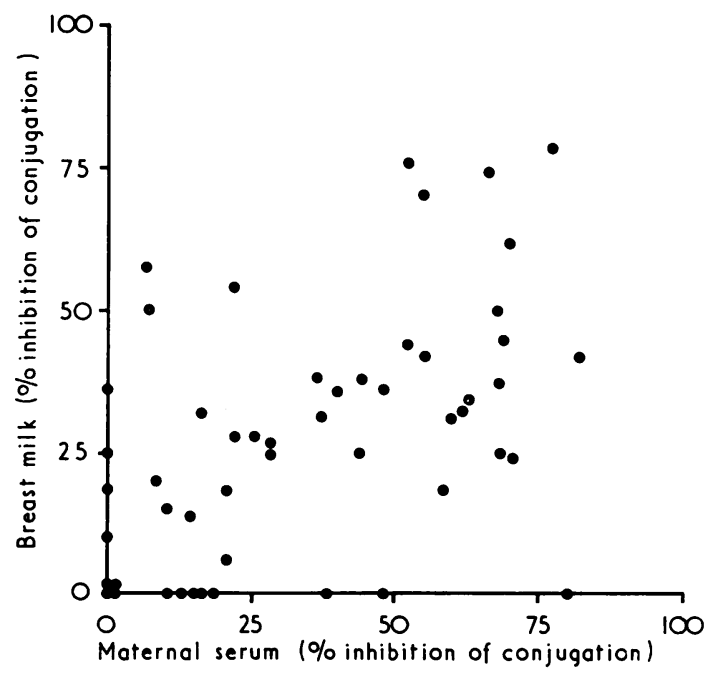

Frg. 3.-Relation between inhibitory activity of maternal serum and breast milk at 6th day post partum. 


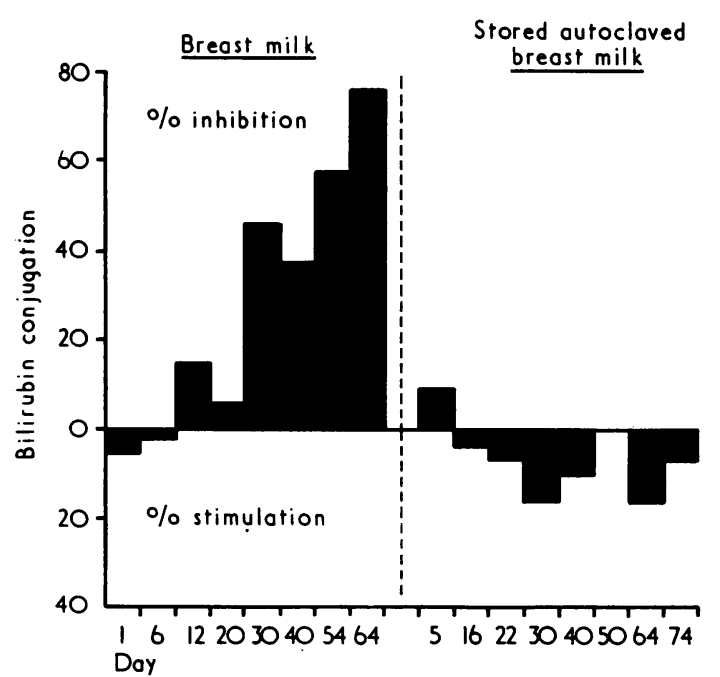

FIG. 4.-Effect of storage at $-20^{\circ} \mathrm{C}$ in the inhibition of bilirubin conjugation by breast milk. The determination on each day is the mean of duplicate analyses.

develop in sterilized bank milk. Inhibitory activity did not develop in supernatant obtained after centrifugation of the milk.

\section{Discussion}

Neonatal jaundice may be caused by a number of factors. A knowledge of the time of onset of the jaundice and its subsequent course may be helpful in diagnosis. If the onset is in the first 36 hours of life then the jaundice is probably due to haemolysis. If it appears a little later, reaching a peak within the first week, then it is probably due to immaturity of the conjugation mechanisms. If an unconjugated hyperbilirubinaemia persists then the differential diagnosis includes hypothyroidism, congenital defects of bilirubin conjugation, and inhibition of conjugation by substances in maternal milk (Arias et al., 1964) or serum (Lathe and Walker, 1958b; Arias et al., 1965).

The present study was undertaken to determine whether there was any relation between maternal serum and breast milk inhibitors of conjugation and neonatal serum bilirubin levels. All samples were obtained on the 6th day after birth. This time was chosen because the inhibitory activity of normal maternal sera and that of mothers of children with transient familial neonatal jaundice can be clearly distinguished (Arias et al., 1965). The results show that in an unselected series of breastfed infants considerable inhibitory activity may be present in maternal milk and serum but this had no correlation with the degree of jaundice. There is as yet no evidence that the inhibitor found in breast milk in these studies is different from that found in breast milk of mothers of children with breast milk jaundice. This type of jaundice is an unconjugated hyperbilirubinaemia persisting after the immediate postpartum period, the breast milk containing a substance which gives 90 to $100 \%$ inhibition of bilirubin conjugation in rat liver slices. The inhibitory factor may be a steroid, pregnane-3 $\alpha, 20 \beta$-diol (Arias et al., 1964), or it may be other substances (Hargreaves and Piper, 1971). Normal maternal serum also contains an inhibitor of bilirubin conjugation which can be found up to 12 days post partum. Transient familial neonatal hyperbilirubinaemia is due to excessive amounts of inhibitor in maternal serum, the level is such that it gives almost $100 \%$ inhibition at 6 days post partum in these cases (Arias et al., 1965).

This study emphasizes that factors other than inhibitory substances in milk and serum are involved in the production of neonatal hyperbilirubinaemia. In the absence of haemolytic disease one of the main causes of neonatal jaundice is the slow development of the bilirubin conjugation system. This may be the bilirubin carrier protein ( $\mathrm{Y}$ protein) in the liver (Levi, Gatmaitan, and Arias, 1969), or the conjugating enzyme glucuronyl transferase (Lathe and Walker, 1958b). The nutritional state of the infant has been suggested as a cause of early neonatal hyperbilirubinaemia (British Medical Journal, 1970). This has experimental support from the work of Flint, Lathe, and Ricketts (1963) who observed that starvation delayed the development of conjugation mechanisms. The production of neonatal jaundice is the result of the interaction of a number of complex factors.

The investigation of breast milk jaunduce is further complicated by the observation that inhibitory activity can develop in breast milk kept at $-20^{\circ} \mathrm{C}$. The mechanism of this is not yet known though it has clinical implications. It was thought possible that such inhibition could develop in breast milk kept in a bank. The specimens so far tested have not shown this, suggesting that autoclaving prevents development of the inhibitory activity.

We thank our paediatric and obstetric colleagues for permission to investigate their patients, and the South Western Regional Hospital Board for financial assistance.

REFERENCES

Arias, I. M. and Gartner, L. M. (1970). Breast-milk jaundice. British Medical fournal, 4, 177. 
Arias, I. M., Gartner, L. M., Seifter, S., and Furman, M. (1964). Prolonged neonatal unconjugated hyperbilirubinemia associated with breast feeding and a steroid (pregnane3(alpha), 20(beta)-diol), in maternal milk that inhibits glucuronide formation in vitro. Fournal of Clinical Investigation, 43, 2037.

Arias, I. M., Wolfson, S., Lucey, J. F., and McKay, R. J., Jr. (1965). Transient familial neonatal hyperbilirubinaemia. Fournal of Clinical Investigation, 44, 1442.

British Medical fournal (1970). Editorial. Breast milk jaundice, $3,178$.

Brown, A. K., and Zuelzer, W. W. (1957). Studies in hyperbilirubinemia. 1. Hyperbilirubinemia of the newborn unrelated to isoimmunization. American fournal of Diseases of Children, 83, 263.

Flint, M., Lathe, G. H., and Ricketts, T. R. (1963). The effect of undernutrition and other factors on the development of glucuronyl transferase activity in the new born rabbit. Annals of the New York Academy of Sciences, 111, 295.

Hargreaves, T., and Piper, R. F. (1971). Breast milk jaundice: effect of inhibitory breast milk and $3 \alpha, 20 \beta$-pregnanediol on glucuronyl transferase. Archives of Disease in Childhood, 46, 195.

Lathe, G. H., and Walker, M. (1958a). The synthesis of bilirubin glucuronide in animal and human liver. Biochemical fournal, 70, 705 .
Lathe, G. H., and Walker, M. (1958b). Inhibition of bilirubin conjugation in rat liver slices by human pregnancy and neonatal serum and steroids. Quarterly Fournal of Experimental Physiology and Cognate Medical Sciences, 43, 257.

Levi, A. J., Gatmaitan, Z., and Arias, I. M. (1969). Two hepatic cytoplasmic protein fractions, $\mathbf{Y}$ and $Z$, and their possible role in the hepatic uptake of bilirubin, sulfobromophthalein and other anions. Fournal of Clinical Investigation, 48, 256.

Ramboer, C., Thompson, R. P. H., and Williams, R. (1969) Controlled trials of phenobarbitone therapy in neonatal jaundice. Lancet, 1, 966.

Sacrez, R., Lévy, J. M., Scheppler, E., and Klein, M. (1960) Relations entre l'ictère physiologique du prématuré et la toxémie tardive de la grossesse: étude clinique. Annales de Pédiatrie, 7, 219.

Sjöstedt, S., Engleson, G., and Rooth, G. (1958). Dysmaturity. Archives of Disease in Childhood, 33, 123.

Wood, B. S. B., Culley, P. E., Waterhouse, J. H., and Powell, D. J. (1962). Factors influencing neonatal jaundice. Archives of Disease in Childhood, 37, 371.

Correspondence to Dr. T. Hargreaves, Area Department of Pathology, Church Lane, Heavitree, Exeter, Devon EX2 5AD. 